\title{
Reexamining age, race, site, and thermometer type as variables affecting temperature measurement in adults - A comparison study Linda S Smith*
}

\author{
Address: School of Nursing, Oregon Health \& Science University, Klamath Falls, Oregon, USA \\ Email: Linda S Smith* - smilinda@ohsu.edu \\ * Corresponding author
}

This article is available from: http://www.biomedcentral.com//472-6955/2/I

(C) 2003 Smith; licensee BioMed Central Ltd. This is an Open Access article: verbatim copying and redistribution of this article are permitted in all media for any purpose, provided this notice is preserved along with the article's original URL.

\begin{abstract}
Background: As a result of the recent international vigilance regarding disease assessment, accurate measurement of body temperature has become increasingly important. Yet, trusted lowtech, portable mercury glass thermometers are no longer available. Thus, comparing accuracy of mercury-free thermometers with mercury devices is essential. Study purposes were I) to examine age, race, site as variables affecting temperature measurement in adults, and 2) to compare clinical accuracy of low-tech Galinstan-in-glass device to mercury-in-glass at oral, axillary, groin, and rectal sites in adults.

Methods: Setting 176 bed accredited healthcare facility, rural northwest US

Participants Convenience sample $(\mathrm{N}=120)$ of hospitalized persons $\geq 18$ years old.

Instruments Temperatures $\left({ }^{\circ} \mathrm{F}\right)$ measured at oral, skin (simultaneous), immediately followed by rectal sites with four each mercury-glass (BD) and Galinstan-glass (Geratherm) thermometers; 10 minute dwell times.

Results: Participants averaged 61.6 years (SD 17.9), 188 pounds (SD 55.3); $61 \%$ female; race: $85 \%$ White, $8.3 \%$ Native Am., 4.2\% Hispanic, I.7 \% Asian, 0.8\% Black. For both mercury and Galinstanglass thermometers, within-subject temperature readings were highest rectally; followed by oral, then skin sites. Galinstan assessments demonstrated rectal sites $0.91^{\circ} \mathrm{F}>$ oral and $\cong 1.3^{\circ} \mathrm{F}>$ skin sites. Devices strongly correlated between and across sites. Site difference scores between devices showed greatest variability at skin sites; least at rectal site. $95 \%$ confidence intervals of difference scores by site $\left({ }^{\circ} \mathrm{F}\right)$ : oral $(0.142-0.265)$, axilla $(0.167-0.339)$, groin $(0.037-0.32 \mathrm{I})$, and rectal $(-$ $0.1 \mathrm{II}-0 . \mathrm{III}$ ). Race correlated with age, temperature readings each site and device.

Conclusion: Temperature readings varied by age, race. Mercury readings correlated with Galinstan thermometer readings at all sites. Site mean differences between devices were considered clinically insignificant. Still considered the gold standard, mercury-glass thermometers may no longer be available worldwide. Therefore, mercury-free, environmentally safe low-tech Galinstan-in-glass may be an appropriate replacement. This is especially important as we face new, internationally transmitted diseases.
\end{abstract}




\section{Background}

All health services need reliable, valid, readily available and accessible body temperature assessment devices. Obviously, body temperature assessments are key diagnostic indicators. Yet, the measurement of human body temperature has recently been cause for concern. Since Wunderlich's seminal work [1], mercury has been and continues to be the "gold standard" for temperature measurement [2-5]. Current values used to define fever are founded on Wunderlich's classic temperature research efforts. However, the manufacture, distribution, and sales of mercury filled fever thermometers has been banned or restricted in at least ten US states and US federal legislation to restrict mercury thermometer availability nationwide, is pending. Similar restrictions are occurring globally.

As increased disease detection and management efforts continue worldwide, the key physical indicator of body temperature becomes critically important [6]. Thus, study purposes were 1) to examine age, race, and site as variables affecting temperature measurement in adults, and 2) to compare the clinical accuracy of the low-tech Galinstan-in-glass device to mercury-in-glass at oral, axillary, groin, and rectal sites in persons 18 and older.

Numerous variables are known to influence body temperature measures. These variables include age [7-10], race $[11,12]$, pharmacologic agents [13-15], infectious agents $[1,16,17]$, exercise $[18,19]$, device dwell times $[20-23]$, device type $[1,20,24-28]$, and body site $[5,20,26,29-31]$. For this study, dwell times were consistent for all readings; study variables included age, race, device type, and body site.

Chosen temperature assessment sites for this investigation were oral, axillary, groin, and rectal. The oral site is inappropriate and unsafe for patients younger than six but well accepted by the general public. Possible oral site reading errors include the influence of food/fluids, smoking, placement technique, oral seal, and hypothermic status. The non-invasive axillary skin site is commonly used and accepted with infants and generally familiar and accepted by adults. Possible assessment errors include the influence of ambient temperature, hypothermic status, fatty layers, dominant arm muscle mass, skin folds, and circulatory differences due to asymmetric thoracic cavity organ placement $[21,32,33]$.

Other non-invasive skin sites are the groin sites, located bilaterally directly over the femoral artery in the inguinal area. Though identified as viable sites in infants and neonates $[23,34,35]$, other than as a potential prediction of psychosexual arousal, [36,37] groin temperature sites have not been well investigated in adult population groups. For adults, the groin site is potentially better tolerated and less invasive than rectal.

The rectal temperature site requires a thermometer placement in the patient's rectum, beyond the anal sphincter. Though not well tolerated by adults, rectal is a common site in young children and considered to be accurate in children and infants. However, rectal readings may be imprecise, especially for older adults, due to presence of stool, heavy lower extremity size, decreased rectal circulation, and mobility variations [21,38-40]. Rectal lag has been identified as the lag time or delayed response of rectal versus core body temperatures. This lag time is especially evident during core temperature fluctuations [41$43,21]$. Rectal and oral sites have the disadvantage of body fluid contact.

Study devices for this investigation included the low-tech, portable, lightweight, and sterilizable mercury-in-glass and Galinstan-in-glass thermometers. Low-tech glass thermometers present no concern regarding battery disposal or power source competence. Both thermometer types can be used with oral, skin, or rectal sites. Both thermometer types can be person-specific, preventing cross transfer and cross contamination of bio-hazardous materials.

Mercury-in-glass thermometers may no longer be available; and if broken, become potentially toxic to patient and environment. Galinstan-in-glass is a metal alloy-in-glass thermometer that is safe to the patient/environment [44]; identified internationally as the in-glass mercury substitute thermometer. It is easy to read (both $\mathrm{F}$ and $\mathrm{C}$ measures) and has only a slightly higher cost than mercury-inglass devices. Though mercury-free, the Galinstan-in-glass product, as with all glass thermometers, requires careful handling due to risk of accidental injury from breakage.

\section{Significance}

Except for small, unpublished pilot work by Smith $(\mathrm{N}=$ 39) [45] this investigation is the first to assess and compare the Galinstan-in-glass thermometer device in humans. A true need exists to compare this mercury substitute thermometer with the mercury device. This need is especially critical because these low-tech mercury free devices are ideal additions to hazardous materials (HAZMAT) units, emergency, and law enforcement vehicles.

\section{Methods}

A descriptive, correlation design was used to determine within-subject mean differences between and among sites and instruments. Descriptive statistics described the overall sample and temperature measures. Subjects were their own controls. Alpha was set at 0.05 . 


\section{Sample and Setting}

A convenience sample $(\mathrm{N}=120)$ of adult in-patients in a rural pacific northwest accredited hospital and medical center was obtained. Participants were English-speaking currently hospitalized men and women who were at least 18 years of age, mentally competent, and willing to participate. Participants had palpable femoral pulses and competent rectums. Oral temperature assessments occurred $\geq$ 15 minutes post oral food/fluids [38]. This was assessed by asking participants, "when did you last eat or drink anything?" Data collection took place from August to October, 2002.

\section{Human Subjects}

In addition to Oregon Health \& Science University approval, IRB approval was also obtained through the active medical center review board. All participants signed informed consent documents prior to data collection. A copy of the consent form was given to participants immediately following written consent. A copy of all temperature data was handed to participants, after their temperatures were assessed.

\section{General Procedures}

All temperature measurement devices were assessed for accuracy prior to study use. A swirling water bath was used with identified temperature levels and controls; consistent with procedures used by previous researchers $[23,34]$.

An ASTM mercury-in-glass thermometer with traceable certification of accuracy (against NIST standards) was used to assess water bath temperatures. All devices used read within $\pm 0.2^{\circ} \mathrm{F}$ at three different temperature settings (range between $97-102^{\circ} \mathrm{F}$ ). An ambient temperature thermometer with NIST traceable certificate of compliance was also used. A count-up timer for precise time intervals was employed.

\section{Instruments}

Temperatures were simultaneously measured at two oral and four skin sites, immediately followed by rectal sites. Four (each) individual, sheathed mercury-in-glass and Galinstan-in-glass thermometers were used for these temperature measurements. Environmental air temperature was recorded. All temperature readings were reported in degrees Fahrenheit. An equal dwell time of ten minutes was used for each measurement to control time as a factor affecting instruments and sites [21-23,46-48].

Between use, thermometers were cleaned as follows:

1. Cool soap and water bath, with two-minute agitation and cold rinse, times three
2. Soak in 1:10 mixture of bleach/water minimum of 6 hours, followed by cool soap and water bath, with two minute agitation, and cold rinse [49-51]. The Australian Resuscitation Council has accepted that bleach can be used for cleansing of resuscitation equipment [51].

3. Soak in full strength isopropyl alcohol minimum of 12 hours, followed by cold water rinse times two.

\section{Dry on clean, dry towel}

\section{Procedure}

The principal investigator and a trained research assistant performed all procedures. Right and left readings for oral (temperature oral), axillary (temperature axilla), groin (temperature groin), and rectal (temperature rectal) were taken using sheathed oral/skin mercury-in-glass thermometers and sheathed rectal or oral/skin or rectal Galinstan-in-glass thermometers (respectively). Participants were instructed beforehand to keep lips closed once oral thermometers were in place. Right/left device type locations for oral, axilla, and groin were random.

- Oral readings were simultaneous (Galinstan on one side; mercury on the other) bilateral measures at the location of the sublingual artery (pocket of tissue at the base of the tongue, just above the sublingual artery) $[21,52]$.

- Axillary readings were simultaneous (mercury on one side; Galinstan on the other) bilateral measures deep into mid-axilla [apex] [10,23,34,53] with client's arms adducted. Axillary and groin site thermometers were placed immediately after placement of oral.

- Groin readings were simultaneous (Galinstan on one side; mercury on the other) bilateral at the location of the femoral artery. The technique for groin/femoral/inguinal temperature readings involved gentle slight abduction of the patient's leg, location of the femoral pulse, placement of the sheathed thermometer on and lateral to the pulse site, and slight adducting of the leg to create a seal $[23,34]$.

- Technique for rectal included two sheathed thermometers (one mercury, one Galinstan) with water-soluble lubrication, inserted together to a depth of five cms $[21,54,55]$. Once the rectal thermometers were inserted, the principal investigator's gloved thumb and forefinger held the top safety grip on the mercury and top $0.5 \mathrm{~cm}$ of the $12.7 \mathrm{~cm}$ long Galinstan. All thermometers began at a reading below $96^{\circ} \mathrm{F}$. This reading was chosen because the mercury-in-glass thermometers were not calibrated below $96^{\circ} \mathrm{F}$. Prior to recording, both observers agreed upon all measurement readings. 
Table I: Description of Sample

\begin{tabular}{|c|c|c|c|c|c|c|}
\hline Variable & Mean & & & SD & Range & \\
\hline Age (years) & 61.6 & & & 17.9 & 19 & 94 \\
\hline Weight (pounds) & 188 & & & 55.3 & 100 & 400 \\
\hline Weight (estimated Kgs) & 85.4 & & & 25.12 & 45.5 & 181.8 \\
\hline Room Temperature $\left({ }^{\circ} \mathrm{F}\right)$ & 74 & & & 1.19 & 71.2 & 78.3 \\
\hline Culture/race & White & Asian & $\begin{array}{l}\text { Native Ameri- } \\
\text { can }\end{array}$ & Hispanic & Black & Total \\
\hline \multicolumn{7}{|l|}{ Gender } \\
\hline Male & 42 & 0 & 2 & 2 & 1 & 47 \\
\hline Female & 60 & 2 & 8 & 3 & 0 & 73 \\
\hline Total & 102 & 2 & 10 & 5 & 1 & 120 \\
\hline
\end{tabular}

Upon completion of temperature assessments, the room temperature was assessed and recorded and the patient was returned to a comfortable, resting position. A carbon copy of temperature readings was given to each participant.

\section{Results}

\section{Description of Sample}

Although 120 individuals participated in this study, not all paired readings were possible for all participants because mercury-in-glass thermometers were calibrated only as low as 96 degrees $\mathrm{F}$. When temperature readings fell below this level, no evaluation could be recorded and thus, paired readings and difference scores were not possible.

Participants averaged 61.6 years old (SD 17.9) and 188 pounds (SD 55.3); they were $61 \%$ female. Eighty-five percent self-reported as having a White racial heritage. Native-American was the second most commonly reported racial heritage at $8.3 \%$ followed by Hispanic (4.2\%) Asian (1.7\%) and Black (.8\%). These percentages are consistent with the racial mix within this rural community. More females than males volunteered as research participants (see Table 1).

\section{Comparing temperature sites}

For both the mercury-in-glass and Galinstan-in-glass thermometers, temperature readings by site were as follows: $\mathrm{R}$ $>\mathrm{O}>$ Skin (axilla and groin). That is, within-subject temperature assessments were highest rectally, followed by oral, and then groin or axillary skin sites. This result was as expected [56-59].

To examine same-device temperature reading differences across body sites, mean difference scores were calculated along with standard deviations (see Table 2).

\section{Comparing temperature devices}

See Table 3 for a description of within site differences between the two devices.

As suggested by Bland and Altman [60] to further examine variability of mean temperature differences between devices, a box plot diagram was formulated (see Figure 1). The question is: Do measurements from different devices sufficiently agree and how different are the two methods [60]? Thus, a scatter plot of devices by site was devised (see Figure 2) followed by plots of the difference between devices by site against their means (see Figures 3,4,5 and 6). According to Bland and Altman [60] this method of plotting differences "... allows us to investigate any possible relationship between the measurement error and the true value. We do not know the true value, and the mean of the ... measurements is the best estimate we have," (p. 308).

Further examination of differences included repeatability analyses. If differences were normally distributed, the expectation was that $95 \%$ of all sample means of differences, based on this sample, would fall within this confidence interval. An analysis of the limits of agreement was computed based on the mean and two standard deviations (precision) of the difference between devices by sites [60]. According to Gardner and Altman [61] confidence intervals are a more useful and informative approach than $P$ values because they present a range of values. For confidence intervals of difference scores, see Table 4 . However, caution is expressed due to the skewed histograms of difference scores. Thus, the assumption of Normality may be invalid $[60,61]$. 
Table 2: Mean temperature differences between sites $\left({ }^{\circ} \mathrm{F}\right)$ for two devices

\begin{tabular}{|c|c|c|c|c|}
\hline \multicolumn{5}{|c|}{ Mercury-in-glass site differences } \\
\hline Sites & & Mean Difference & SD & $\mathrm{N}$ \\
\hline To> & $\operatorname{Tg}$ & $.396^{\circ} \mathrm{F}$ & .83 & 119 \\
\hline To> & Tx & $.397^{\circ} \mathrm{F}$ & .75 & 119 \\
\hline $\operatorname{Tg}>$ & Tx & $.000^{\circ} \mathrm{F}$ & .88 & 120 \\
\hline $\mathrm{Tr}>$ & $T x$ & $1.06^{\circ} \mathrm{F}$ & .68 & 117 \\
\hline Tr> & To & $.648^{\circ} \mathrm{F}$ & .62 & 116 \\
\hline $\operatorname{Tr}>$ & $\mathrm{Tg}$ & $1.04^{\circ} \mathrm{F}$ & .76 & 117 \\
\hline \multicolumn{5}{|c|}{ Galinstan-in-glass site differences } \\
\hline Sites & & Mean Difference & SD & $\mathrm{N}$ \\
\hline To> & $\operatorname{Tg}$ & $.380^{\circ} \mathrm{F}$ & .80 & 119 \\
\hline To> & Tx & $.449^{\circ} \mathrm{F}$ & .81 & 119 \\
\hline $\mathrm{Tg}>$ & Tx & $.007^{\circ} \mathrm{F}$ & .75 & 120 \\
\hline $\mathrm{Tr}>$ & Tx & $1.35^{\circ} \mathrm{F}$ & .78 & 117 \\
\hline $\mathrm{Tr}>$ & To & $.913^{\circ} \mathrm{F}$ & .57 & 116 \\
\hline $\operatorname{Tr}>$ & $\mathrm{Tg}$ & $1.29^{\circ} \mathrm{F}$ & .67 & 117 \\
\hline
\end{tabular}

Legend: To - Temperature oral $\mathrm{Tx}$ - Temperature axilla $\mathrm{Tg}$ - Temperature groin $\mathrm{Tr}$ - Temperature rectal

Table 3: Mean temperature differences, SD between devices at four sites ( $\left.{ }^{\circ} \mathrm{F}\right)$

\begin{tabular}{|c|c|c|c|}
\hline Site & Mean Difference (Bias) & SD & $\mathrm{N}$ \\
\hline To: mercury - Galinstan & $.203^{\circ} \mathrm{F}$ & .34 & 119 \\
\hline Tx: mercury - Galinstan & $.253^{\circ} \mathrm{F}$ & .48 & 120 \\
\hline Tg: mercury - Galinstan & $.179^{\circ} \mathrm{F}$ & .79 & 120 \\
\hline Tr: mercury - Galinstan & $-.05^{\circ} \mathrm{F}$ & .31 & 117 \\
\hline
\end{tabular}

Legend: To - Temperature oral $\mathrm{Tx}$ - Temperature axilla $\mathrm{Tg}$ - Temperature groin $\mathrm{Tr}$ - Temperature rectal

Correlation is a quantification of the linear relationship between variables and does not examine the question of agreement. Often used to analyze thermometer reading accuracy, correlation is an estimate of how much two variables change in relation to one another. Perfect correlation does not mean perfect agreement [62]. Altman and Bland [63] identified this as a favorite approach to the comparison of two methods of measurement. Therefore, correlation statistics were established for the purpose of literature comparisons. Furthermore, human body within and between site agreement cannot be assumed. Thus, relationships between and among variables are represented with a correlation table (see Table 5).

No statistically significant correlations were found between difference scores and mean temperatures at each site. That is, variability of difference scores was not correlated with lower or higher temperature readings.

\section{Comparing demographic variables}

No statistically significant correlations were found for temperature readings and variables such as gender, weight, random right/left placement of devices (oral, axilla, groin), and room temperature.

Race significantly correlated with age and mean temperature readings for each site. Age correlated significantly and negatively (the higher the age, the lower the weight) with weight and race (non-whites tended to be younger), as well as oral, axillary, and rectal mean temperature readings (the higher the age, the lower the reading).

\section{Discussion}

Discussion of site comparisons: Contradictions to the one degree Fahrenheit rule

Tradition has dictated to lay and professional caregivers the one degree Fahrenheit rule. Many remember learning about the one degree Fahrenheit estimated difference: rectal site temperatures are about one degree higher than oral which is about one degree higher than axillary sites. As 


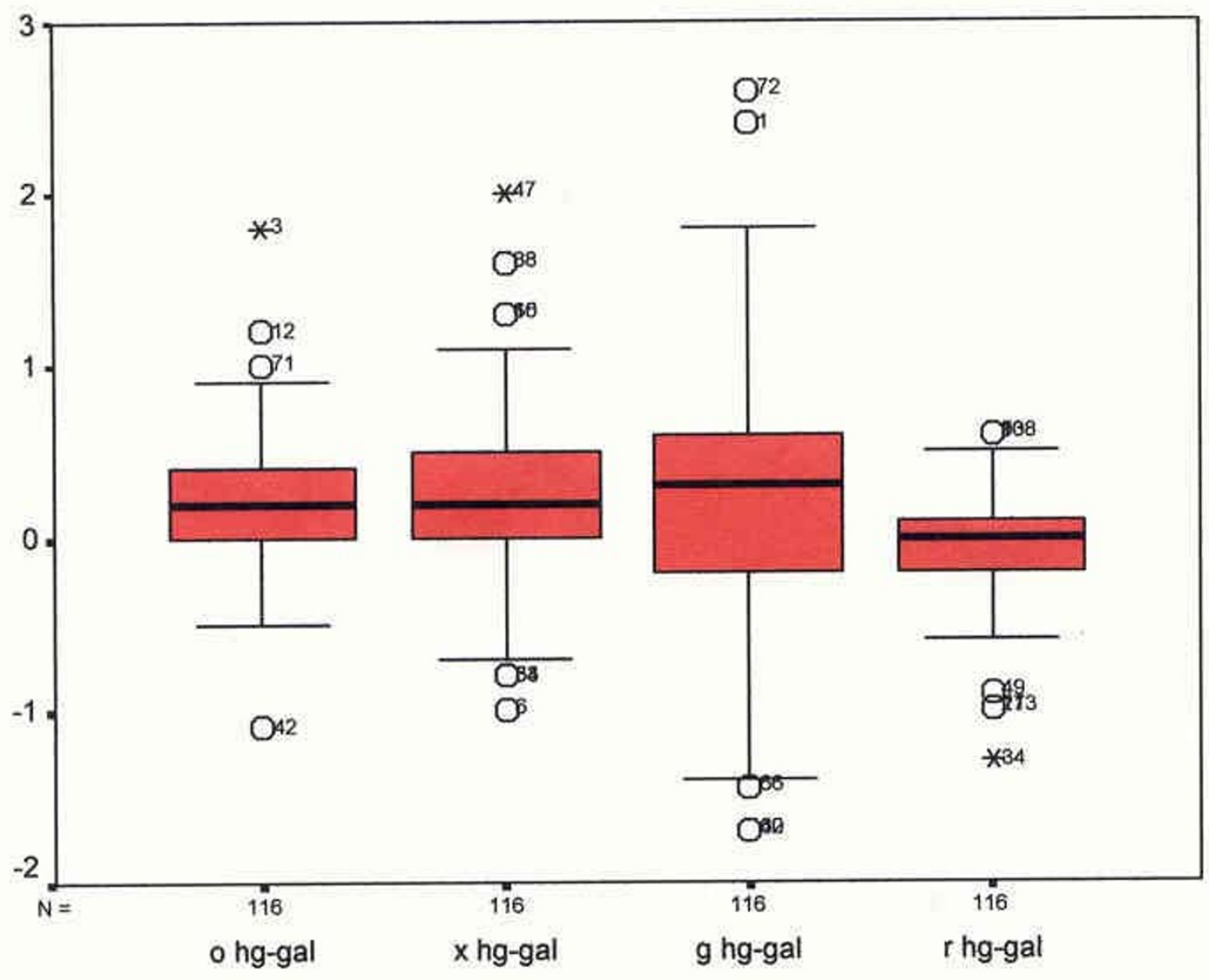

Figure I

Box plot showing mean temperature reading differences and variability between mercury-in-glass and Galinstan-in-glass devices at four sites $\left({ }^{\circ} \mathrm{F}\right)$. Box plot - mean differences by site Mercury/Galinstan pairs

noted in Table 1, this estimate "rule" could not be applied to either device. For the mercury-in-glass device, rectal was $0.64^{\circ} \mathrm{F}$ higher than oral, which was $0.39^{\circ} \mathrm{F}$ higher than groin/axillary sites. Rectal readings were only about one degree Fahrenheit higher than skin sites, not two degrees, as the "rule" would imply.

Importantly, the Galinstan-in-glass readings also represented site differences that were different from the onedegree rule. Though rectal site temperature assessments were slightly less than one degree higher than oral $\left(0.91^{\circ} \mathrm{F}\right.$ above oral), skin sites were only about $1.3^{\circ} \mathrm{F}$ below rectal readings (not the expected two degree estimate).

\section{Discussion of device comparisons}

When comparing within-subject mean differences between the two low-tech temperature devices (BD mercury and Geratherm Galinstan), the smallest differences occurred at the rectal site; the largest differences were recorded at skin sites. Skin site variability concurs with findings from other studies $[10,26,64]$. Skin temperature sites, by their very nature, have innate differences, even with simultaneous side-to-side use and identical dwell times. Macro and microcirculation, fatty layers, muscle mass, and skin pockets may differ bilaterally. Unless the same site and time are measured, body temperature gradients become confounding factors [62]. As expected, 


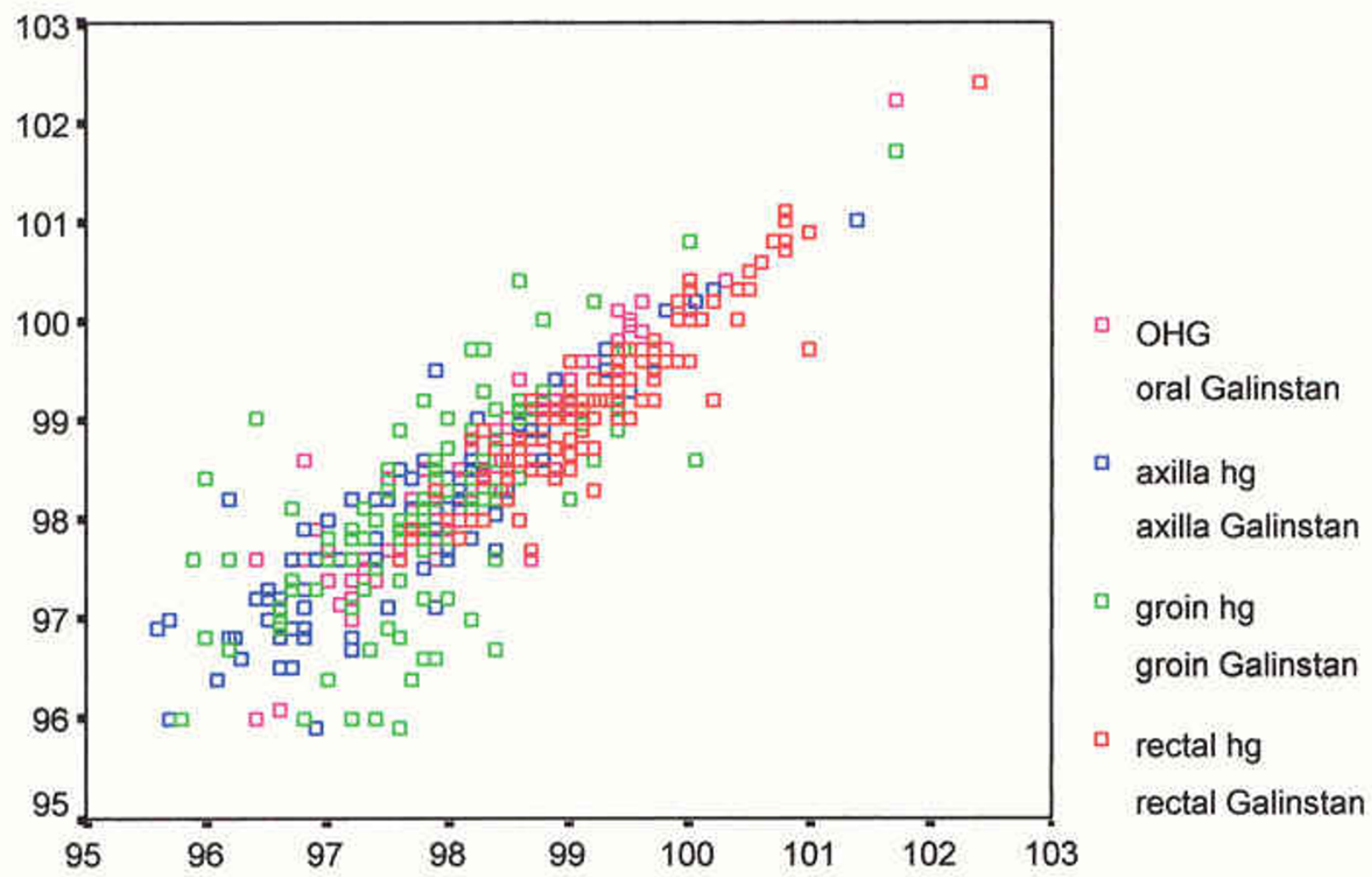

Figure 2

Scatter plot - devices by site $\left({ }^{\circ} \mathrm{F}\right)$. Scatter plot - devices by site Mercury/Galinstan pairs o - oral x-axilla g-groin r-rectal hg-Mercury-in-glass gal-Galinstan-in glass

simultaneous insertion of both thermometers into the moist and protected rectal cavity created a near identical temperature reading match.

Prior to data collection, thermometers were swirling water-bath tested and those with readings greater than \pm $0.2^{\circ} \mathrm{F}$ from water temperature were eliminated from the study. Thus, difference scores at or less than this measure can be deemed to be clinically insignificant. As noted in Table 2, only axillary readings had a difference mean of greater than $0.2^{\circ} \mathrm{F}$ and this mean difference was $0.253^{\circ} \mathrm{F}$. All mean difference scores were less than the described $0.2^{\circ} \mathrm{C}$ level reported by Fallis and Christiani [65] to be clinically significant. Mean difference scores were also less than the $0.36^{\circ} \mathrm{F}$ deemed clinically insignificant by authors Stephen and Sexton [66] and $0.2^{\circ} \mathrm{C}$ deemed clinically insignificant by Fulbrook [58] when he compared axillary and pulmonary artery temperature readings. All but the axillary mean difference scores were at or below the $0.2^{\circ} \mathrm{F}$ accepted variability for inclusion of human temperature assessment devices in clinical investigations $[23,34,65,67]$.

Variability among mean difference scores was assessed in several ways. A box plot showing mean temperature reading differences and variability between mercury-in-glass and Galinstan-in-glass devices at four sites, was constructed (see Figure 1).

Standard deviations were identified for difference scores by site (Table 3), along with a $95 \%$ confidence interval of the mean of difference readings between devices (see Table 4 ). The greatest variability between device readings by site occurred at the two skin sites. This greater variability at skin sites corresponds to findings from other researchers $[22,53,68]$. Ninety-five percent confidence intervals, for the mean of difference readings, were smallest at the rectal site and largest at the groin skin site. 


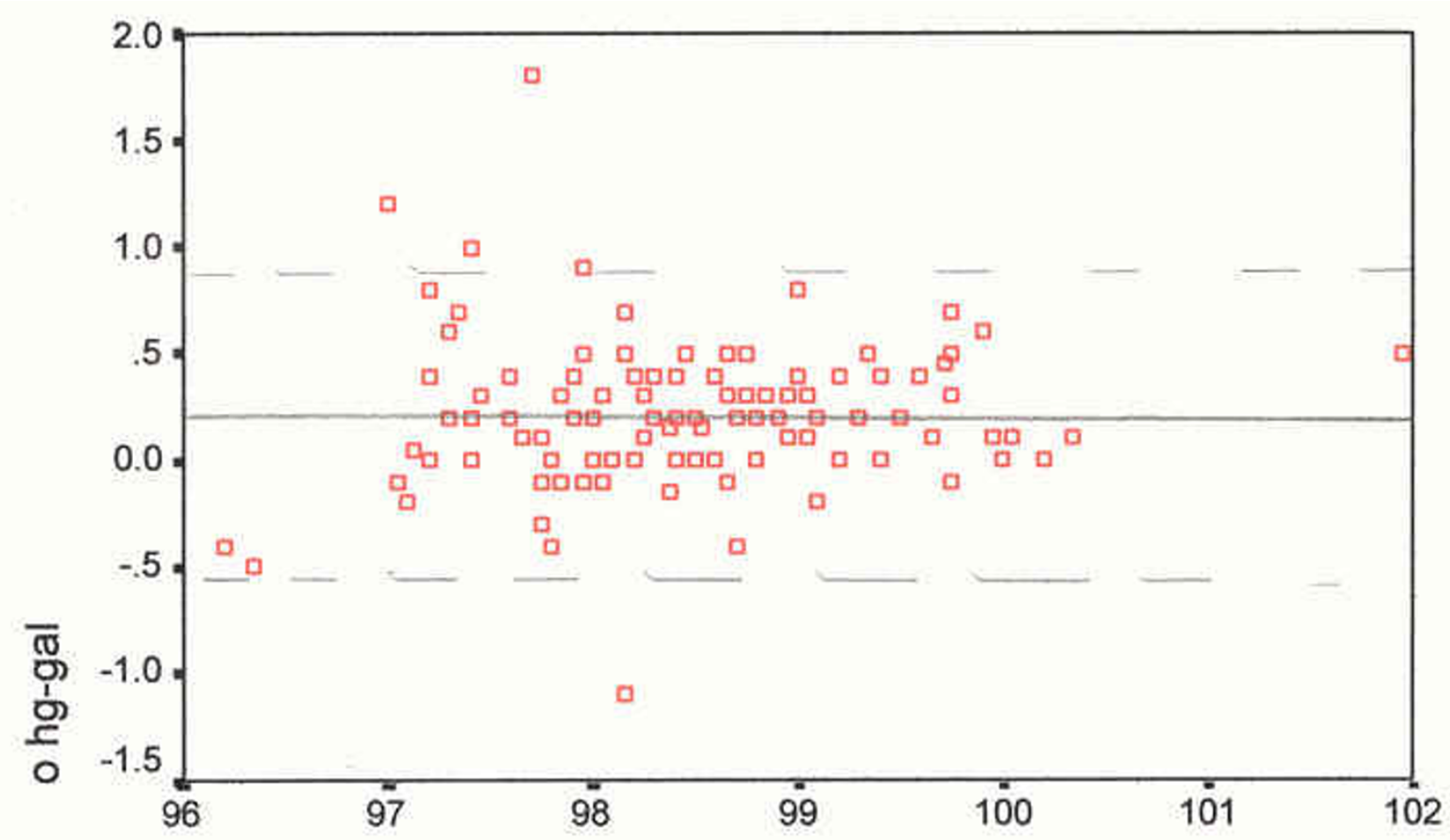

mean oral

Figure 3

Scatter plot of differences, at the oral site, against their mean $\left({ }^{\circ} \mathrm{F}\right)$. The mean difference (mercury minus Galinstan) is $0.20^{\circ} \mathrm{F}$, SD 0.34, skewness 0.676. Oral Device differences against their means mean difference, mercury-Galinstan . . . . 2 SDs from the mean

Correlations between the two thermometer types by site were strong and statistically significant. The strongest correlations were, again as expected, at the rectal and oral temperature sites. Human body asymmetry must be considered as a possible variable for groin and axilla sites. Room temperature was not a significant variable. This result is different from the work of other researchers who found that ambient temperatures significantly affected readings at various sites in infants[57] and various temperature levels in adults [52].

\section{Discussion of demographic variables}

With these study participants, the fairly insignificant role played by gender differs from the work of Nagy [69], Nichols and Kucha [47] and Gillum [12]. In contrast, race was a significant variable for this study. Non-whites were more likely to be younger and have higher temperature readings at each site and with each device. Because subjects were all in-patients in an acute-care hospital setting, and the number of non-white subjects was small $(\mathrm{N}=18$; $15 \%$ of total) no conclusions should be made regarding this finding. However, the influence of race concurs with other investigations $[11,12]$; race may have a significant influence on body temperatures and needs to be studied further. Though the variable of weight was insignificant, age remained an important factor for temperature readings (both devices) at the oral, axillary, and rectal sites. The greater the age, the lower the temperature readings. This finding is consistent with the work of Frankenfield, et al. [8] and Howell [10].

\section{Conclusions}

For both mercury and Galinstan glass thermometers, rectal readings were higher than oral and oral readings were higher than skin site temperature assessments. This finding further verifies similarities between mercury and Galinstan and remains consistent with findings from other studies $[1,26,29,30]$. 


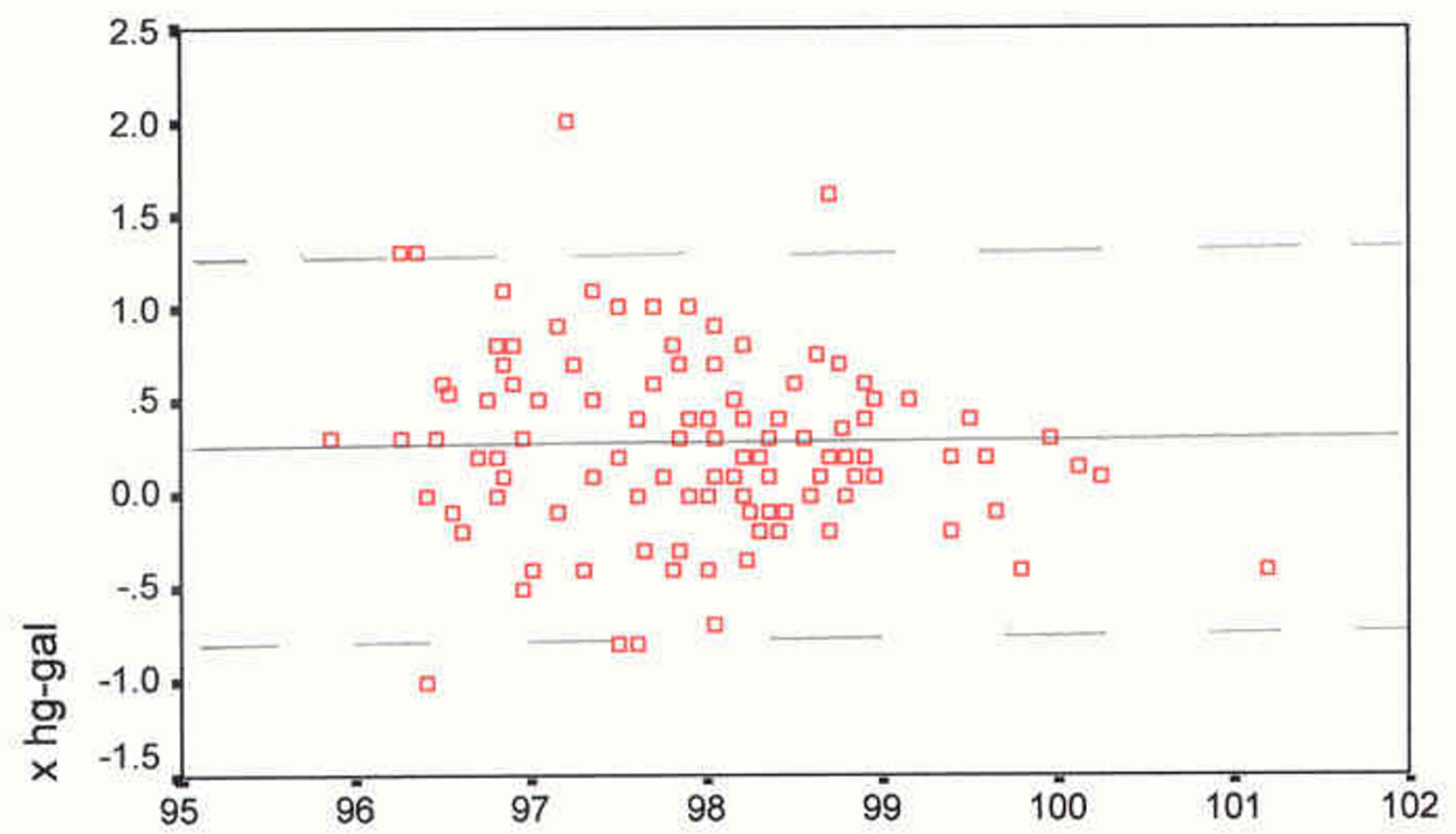

\section{mean axilla}

\section{Figure 4}

Scatter plot of differences, axilla site, against their mean $\left({ }^{\circ} \mathrm{F}\right)$. The mean difference (mercury minus Galinstan) is $0.25^{\circ} \mathrm{F}, \mathrm{SD}$ 0.48 , skewness 0.396. Axilla Device differences against their mean mean difference, mercury-Galinstan - - -

- 2 SDs from the mean

Mercury-in-glass fever thermometers are no longer available in many regions of the US and world. For this study and with these hospitalised participants, the mercury-free Galinstan-in-glass thermometer correlated strongly with the mercury thermometer and may be a practical alternative to mercury filled thermometer products.

For adults, and with careful consideration of site differences and site competence, temperature sites to be considered include all investigated sites - rectal, oral, axillary, and groin. With proper use, non-invasive, nonmucus temperature sites may be safe alternatives to more invasive, less acceptable sites.

Limitations of the study include an unblinded, convenience sample of hospitalised patients; although participants demonstrated a wide range of age, weight, and temperature readings. A further limitation is the small number of non-white participants and the greater number, by percent, of female and older volunteers.

\section{Implications}

Temperature assessment accuracy is critically important. False high readings may lead to expensive and painful diagnostic studies and medical interventions. False low readings may lead to greater morbidity and mortality. Accurate readings are critical to the rapid, effective, and precise patient diagnosis process.

All temperatures should be reported and recorded with the added notation of site and device. Patient-specific temperature trending needs to be consistent by site. However, healthcare professionals can no longer assume the one-degree Fahrenheit rule. Product information will need to be clearly conveyed, in professional and lay literature sources, regarding mean differences among temperature sites in humans. Vital sign chart forms (electronic 


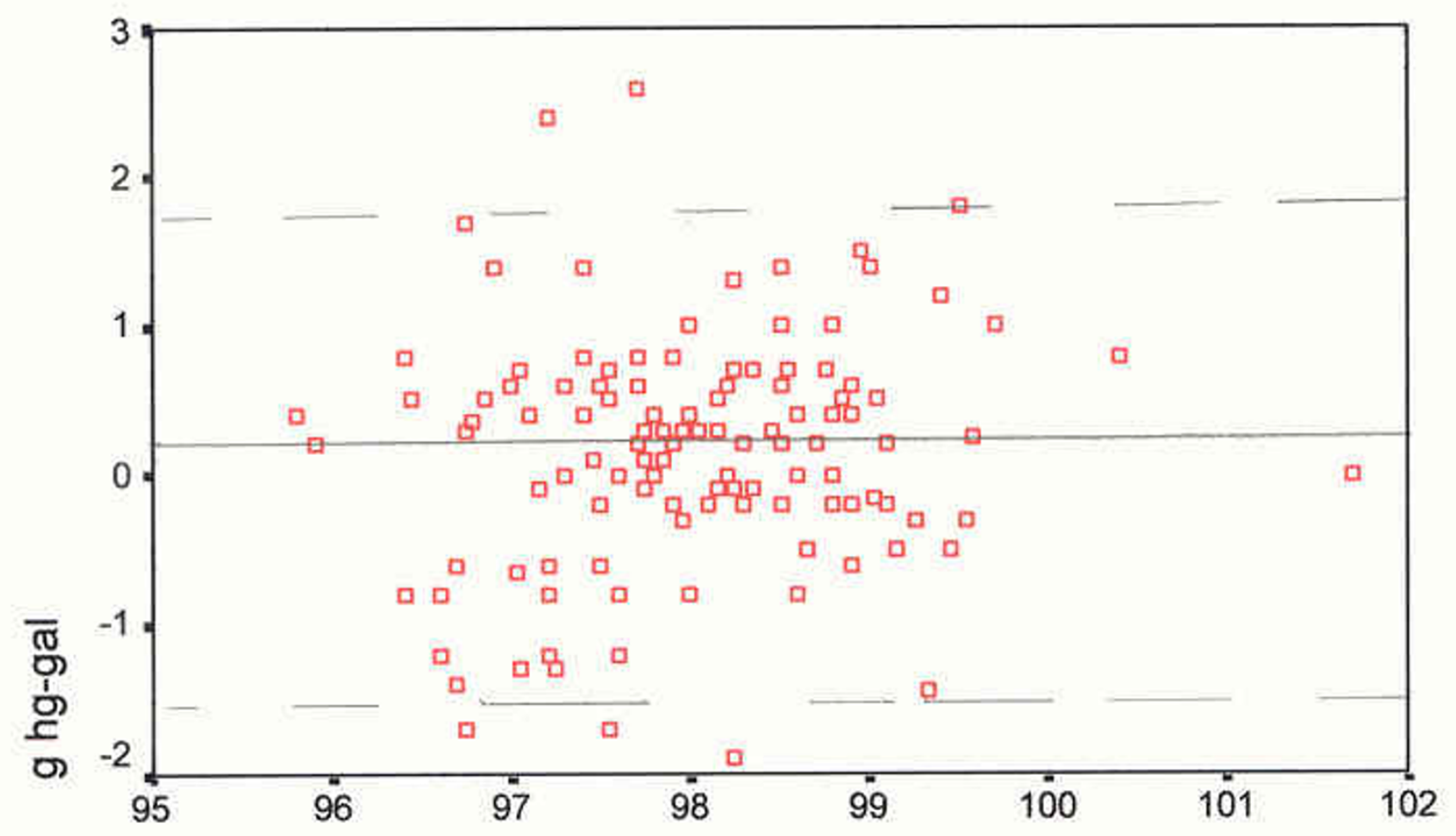

\section{mean groin}

Figure 5

Scatter plot of differences, at the groin site, against their mean $\left({ }^{\circ} \mathrm{F}\right.$ ). The mean difference (mercury minus Galinstan) is $0.18^{\circ} \mathrm{F}$, SD 0.79 , and skewness -0.075 . Groin Device differences against their means Galinstan - . - . 2 SDs from the mean

and paper) need to reflect temperature site as well as device, time, day, and reading in Fahrenheit or Celsius. Health care professionals will need to assist lay caregivers and self-care patients in accurately understanding, recording, and reporting body temperatures. When tracking temperature changes, site and device must be consistent.

Low-tech glass thermometers present the advantage of being portable, storable, lightweight, sterilizable, low in cost, and easy to use. Battery and power source competence is never a question. Person-specific low-tech glass thermometers prevent cross contamination of biological agents and must be considered as essential. Thus, low-tech Galinstan-in-glass thermometers may be an appropriate replacement for mercury filled devices.

\section{Further Research}

Study findings draw attention to needed areas of research for better understanding of the influence of variables such as device, site, race, and age on body temperature assessments. Because comparisons of low-tech Galinstan-inglass and mercury-in-glass body temperature devices are not well described in the literature, it will be essential to replicate this study for comparison of bias and 95\% CI of the bias between these two devices by site. The recording of temperatures using all four sites over time, with a sample of ill and well individuals, would add to knowledge of how different variables affect temperature readings.

The issue of race must be addressed as a potential body temperature variable. Furthermore, age, as identified in this study, may be a critically important indicator relative to how healthcare professionals define and treat body temperature alterations. The groin temperature site, 


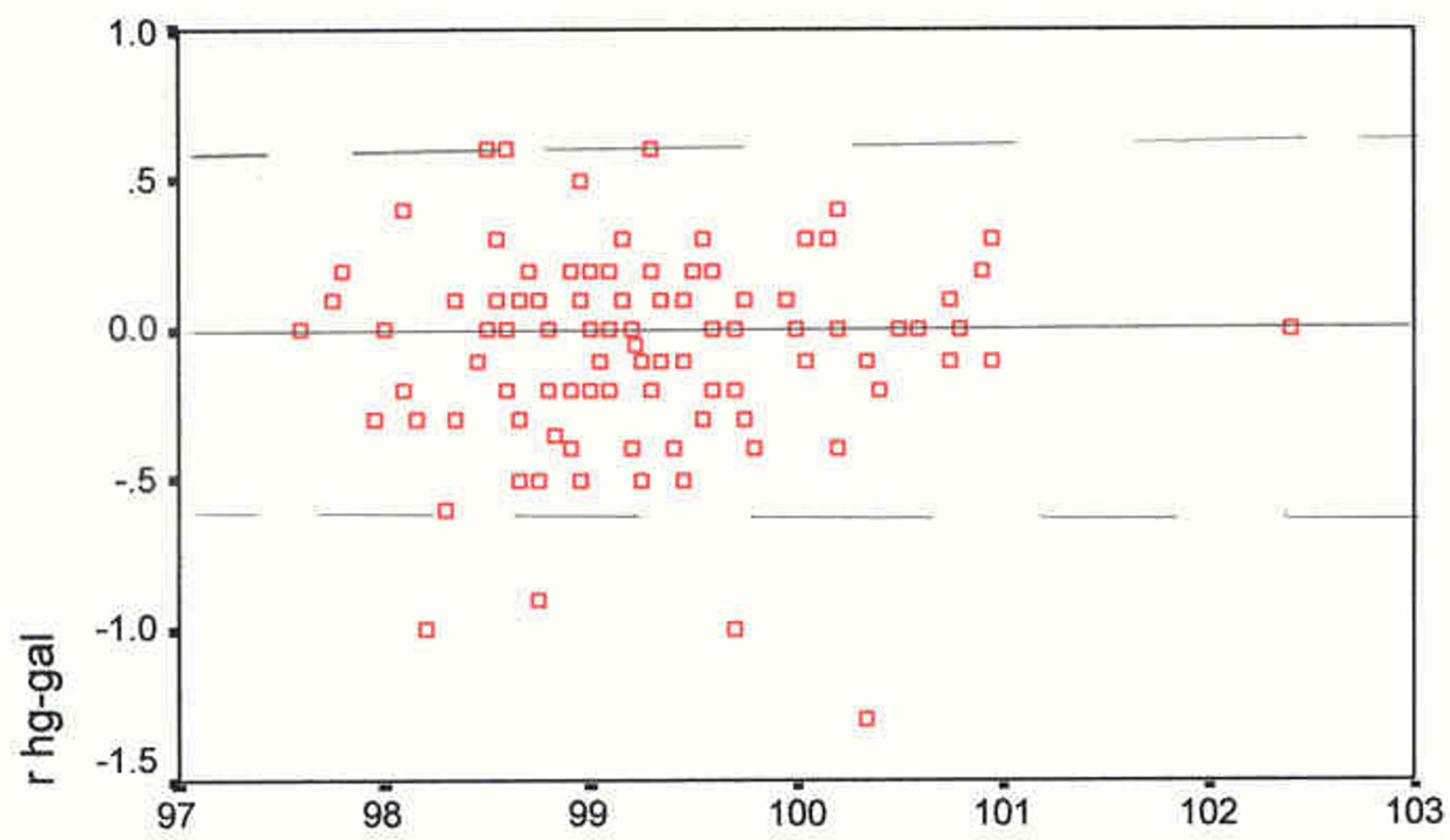

mean rectal

\section{Figure 6}

Scatter plot of differences, at the rectal site, against their mean $\left({ }^{\circ} \mathrm{F}\right)$. The mean difference (mercury minus Galinstan) is $-0.06^{\circ} \mathrm{F}$, SD 0.3I, and skewness - I.04. Rectal Device differences against their means stan - . - . - 2 SDs from the mean mean difference, mercury-Galin-

Table 4: $95 \%$ confidence intervals of difference scores by site

\begin{tabular}{lll}
\hline Site & Lower $\left({ }^{\circ} \mathrm{F}\right)$ & Upper $\left({ }^{\circ} \mathrm{F}\right)$ \\
\hline Oral & 0.142 & 0.265 \\
Axilla & 0.167 & 0.339 \\
Groin & 0.037 & 0.321 \\
Rectal & -0.111 & 0.111 \\
\hline
\end{tabular}

though demonstrating greater mean difference variability and not well studied in adults, may be a good alternative to rectal site temperature assessment. This conclusion, however, cannot be made without further investigation.

Use and study of low-tech Galinstan-in-glass thermometers during biological epidemics would provide additional information regarding the practical application and efficacy of this device during times of extreme international need.

\section{List of abbreviations}

Oral temperature site: Oral

Axillary temperature site: Axilla 
Table 5: Correlations between variables (two devices each site)

\begin{tabular}{llll}
\hline Variable pair & Pearson r & Significance (2-tailed) & $N$ \\
\hline Oral Hg:Galinstan & .929 & $<.001$ & 119 \\
Axilla Hg:Galinstan & .886 & $<.001$ & 120 \\
Groin Hg:Galinstan & .701 & $<.001$ & 120 \\
Rectal Hg:Galinstan & .927 & $<.001$ & 117 \\
Demographic variables and mean temperature readings by site & & & \\
Race: Mean Oral & .264 & .004 & 119 \\
Race: Mean Axilla & .284 & .002 & 120 \\
Race: Mean Groin & .300 & .001 & 120 \\
Race: Mean Rectal & .227 & .014 & 117 \\
Race: age & -.291 & .001 & 119 \\
Age: Weight & -.269 & .001 & 117 \\
Age: Mean Oral & -.308 & .001 & 118 \\
Age: Mean Axilla & -.332 & $<.001$ & 119 \\
Age: Mean Groin & -.077 & .406 & 119 \\
Age: Mean Rectal & -.193 & .037 & 117
\end{tabular}

Groin temperature site: Groin

Rectal temperature site: Rectal

Becton Dickinson Corporation: BD

Standard deviation: SD

Number of participant readings: $\mathrm{N}$

Mercury: $\mathrm{Hg}$

Galinstan: Gal

O: Oral

X: Axillary

G: Groin

R: Rectal

\section{Competing interests}

Thermometer devices and sheaths were donated by BD (mercury-in-glass) and RG Medical Diagnostics (Galinstan-in-glass). Funding for this investigation was received by the Oregon Health \& Science University (OHSU) from two supporting sponsors: Geratherm Medical Diagnostic Systems and RG Medical Diagnostics. Funding requests were initiated by OHSU staff. Grant sources of the study had no role in study design, data collection, data analysis/ interpretation, or report writing.

\section{Authors' contributions}

The principal investigator (manuscript author) formulated and implemented all aspects of this study and report.

\section{Acknowledgements}

The author of this investigation wishes to acknowledge the financial support, as received by OHSU, of two study sponsors: Geratherm Medical Diagnostic Systems and RG Medical Diagnostics. The donation of thermometer devices from BD Corporation and RG Medical Diagnostics is also acknowledged and sincerely appreciated. Thanks go to three research assistants: Deborah James, Aubrey Sharp, and Denise Stiltner. Finally, sincere appreciation is expressed to all of the staff and volunteering patients of the Merle West Medical Center, without whom this investigation could not have taken place.

\section{References}

I. Wunderlich CA: On the temperature in diseases: A manual of medical thermometry London: The New Sydenham Society 21871. Original work published 1870 in Stuttgart: Ebner \& Seubert

2. Sganga A, Wallace R, Kiehl E, Irving T and Witter L: A comparison of four methods of normal newborn temperature measurement MCN, Am J Matern Child Nurs 2000, 25(2):76-79.

3. Hooker EA, Smith SW, Miles T and King L: Subjective assessment of fever by parents: Comparison with measurement by noncontact tympanic thermometer and calibrated rectal glass mercury thermometer Ann Emerg Med 1996, 28(3):313-317.

4. Clarke $S$ : Use of thermometers in general practice $B M J 1992$, 304(6832):961-963.

5. Muma BK, Treloar DJ, Wurmlinger K, Peterson E and Vitae A: Comparison of rectal, axillary, and tympanic membrane temperatures in infants and young children Ann Emerg Med 1991, 20(10):4I-44.

6. Centers for Disease Control and Prevention: Centers for Disease Control and Prevention MMWR 2003, 52(I 2):255-256.

7. Dharmarajan TS, Bullecer MF and Gorich G: Drug-related hyperthermia J Am Med Directors Association 200I, 2(4): 160-I65.

8. Frankenfield DC, Cooney RN, Smith JS and William A: Age-related differences in the metabolic response to injury J Trauma 2000, 48(I):49+.

9. Anderson GS, Meneilly GS. and Mekjavic IB: Passive temperature lability in the elderly Eur J Appl Physiol Occup Physiol 1996, 73:3-4.

10. Howell TH: Axillary temperatures in aged women Age Ageing 1972, I(4):250-254. 
11. McGann KP, Marion GS, Camp L and Spangler JG: The influence of gender and race on mean body temperature in a population of healthy older adults Arch Fam Med 1993, 2(I 2): I 265-1267.

12. Gillum RF: Body temperature and its relationship to demographic and cardiovascular risk factors in a national sample of children and adolescents ] Nat Med Assoc 1992, 84(7):59|-599.

13. Sachdeva K and Ballard JO: Granulocytopenia eMedicine J 3(2):Sections I-10. 2002, February 7, Retrieved April 10, 2002 from emedicine.com on-line journal database, topic 927

14. McGugan EA: Hyperpyrexia in the emergency department Emerg Med 200I, 13(I): II6-I20.

15. Kaplan $\mathrm{HI}$ and Sadock BJ: Pocket handbook of emergency psychiatric medicine Baltimore: Williams and Wilkins 1993.

16. Franz DR, Jahrling PB, Friedlander AM, McClain DJ, Hoover DL, Bryne WR, Pavlin JA, Christopher GW and Eitzen EM: Clinical recognition and management of patients exposed to biological warfare agents JAMA 1997, 278(5):399-4II.

17. Abraham RB, Rudick $V$ and Weinbroum AA: Practical guidelines for acute care of victims of bioterrorism: conventional injuries and concomitant nerve agent intoxication Anesthesiology 2002, 97(4):989-1004.

18. Coyle EF: Physiological determinants of endurance exercise performance / Science \& Med in Sport 1999, 2(3): 181-189.

19. Fischler MP and Reinhard WH: Fever: Friend or enemy? Schweizerische Medizinische Wochenschrift: J Suisse de Medecine 1997, I 27(20):864-870.

20. Craig JV, Lancaster GA, Taylor S, Williamson PR and Smyth RL: Infrared ear thermometry compared with rectal thermometry in children: A systematic review Lancet 2002, 630:603-609.

21. Severine JE and McKenzie NE: Advances in temperature monitoring: A far cry from shake and take Nursing 1997, 27(5 suppl): $1-10$

22. Erickson RS and Meyer LT: Accuracy of infrared ear thermometry and other temperature methods in adults $\mathrm{Am} J$ Crit Care 1994, 3(1):40-54.

23. Bliss-Holtz J: Comparison of rectal, axillary, and inguinal temperatures in full-term newborn infants Nurs Res 1989, 38(2):8587.

24. Prentice $D$ and Moreland J: A comparison of infrared ear thermometry with electronic predictive thermometry in a geriatric setting Geriatr Nurs 1999, 20(6):3।4-317.

25. Leick-Rude MK and Bloom LF: A comparison of temperaturetaking methods in neonates Neonat Netw 1998, 17(5):2 I-37.

26. Schmitz T, Blair N, Falk $M$ and Levine C: $\mathbf{A}$ comparison of five methods of temperature measurement in febrile intensive care patients Am J Crit Care 1995, 4(4):286-292.

27. Fulbrook P: Core body temperature measurement: a comparison of axilla, tympanic membrane and pulmonary artery blood temperature Intensive \& Crit Care Nurs 1997, I3(5):266-272.

28. McKenzie NE: Evaluation of a new, wearable, precision phasechange thermometer in neonates Pediatr Nurs 2003, 29(2): I 17 125.

29. Konopad E, Kerr JR, Noseworthy T and Grace MA: comparison of oral, axillary, rectal and tympanic-membrane temperatures of intensive care patients with and without an oral endotracheal tube J Adv Nurs 1994, 20(I):77-84.

30. Weiss ME and Richards MT: Accuracy of electronic axillary temperature measurement in term and preterm neonates Neonat Netw 1994, 13(8):35-40.

31. Talo H, Macknin ML and Medendorp SV: Tympanic membrane temperatures compared to rectal and oral temperatures $\mathrm{Clin}$ Pediatr 199I, 30(4 suppl):30-35.

32. Keeling EB: Thermoregulation and axillary temperature measurements in neonates: A review of the literature Matern Child Nurs J 1992, 20(3,4): I24-140.

33. Crafts RC: A textbook of human anatomy New York, Wiley Medical 31985

34. Kunnel MT, O'Brien C, Munro BH and Medoff-Cooper B: Comparisons of rectal, femoral, axillary, and skin-to-mattress temperatures in stable neonates Nurs Res 1988, 37(3):162-189.

35. McKenzie NE: Sites Sponsored by Kendall 200I, October 4 [http:// www.graduateresearch.com/thermometry/devices.htm]. January 4 , 2002

36. Rubinsky HJ, Eckerman DA, Rubinsky EW and Hoover CR: Earlyphase physiological response patterns to psychosexual stim- uli: comparison of male and female patterns Arch of Sexual Behav 1987, 16(1):45-56.

37. Rubinsky HJ, Hoon PW, Eckerman DA and Amberson Jl: Groin skin temperature: testing the validity of a relatively unobtrusive physiological measure of psychosexual arousal Psychophysiology 1985, 22(4):488-492.

38. Blainey CG: Site selection in taking body temperature $\mathrm{Am}$ Nurs 1974, 74(10): I859-1861.

39. Resnick B: Dermatologic problems in the elderly Lippincott's primary care practice 1997, I(I): |4-32.

40. Patricio J, Bernades A, Nuno D, Falcao F and Silveira L: Surgical anatomy of the arterial blood supply of the human rectum Surg \& Radiol Anat 1988, I 0(1):71-75.

4I. Ash CJ, Cook JR and Homer LD: The use of rectal temperature to monitor thermal injury in marathon runners in temperate weather Missouri Med 1990, 87(5):298-303.

42. Kneis RC: Temperature measurement in acute care: the who, what, where, when, and how? Emergency Nursing World! 2000 [http://www.enw.org/Research-Thermometry.html]. March I2, 2000

43. McKenzie N: Getting the right reading with thermometers Nurses.com VertMarkets, Inc 2000, March 24 [http://www.nurses.com/

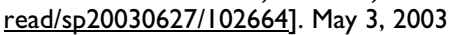

44. Botzenhart K: Toxicological assessment of mercury-free fever thermometers made of glass and filled with a eutectic mixture consisting of gallium, indium, and tin General and Environmental Hygiene, Hygiene Institute at the University of Tubingen . Document translated into English from German 1992, December 2. Available: D-7400 Tubingen I, Silcherstrabe 7, PO Box 1729.

45. Smith LS: Using low-tech thermometers to measure body temperatures in older adults: A pilot study J Gerontol Nurs

46. Eoff MJF, Meier RS and Miller C: Temperature measurement in infants Nurs Res 1974, 23(6):457-60.

47. Nichols GA and Kucha DH: Oral measurements Am J Nurs 1972, 72(6): 1090-1093.

48. Nichols GA and Verhonick PJ: Placement times for oral thermometers: A nursing study replication Nurs Res 1968, I7(2):|59-|6|.

49. Sterilisation of equipment: Policy statement Australian Resuscitation Council (ARC) 200I, May [http://slsa.asn.au/upload/documents/ s418517966202023 3.1\%20sterilisation\%20equipment.PDF]. January I, 2002

50. University of Arkansas for Medical Sciences [UAMS]: UAMS Pneumatic tube system spill procedures (policy) 200I[http:// www.uams.edu/clineng/cepolicy-tube\%20spills.htm]. January I, 2002

5I. Stanton R: Final draft of the joint DHEC/SLED/FBI product to assist law enforcement with incident management: Potential Anthrax letter found South Carolina Department of Health and Environmental Control [DHEC] 200I, October 16 [http:/l www.llr.state.sc.us/fmarshal/sledanthrax.pdf]. January I, 2002

52. Zehner W] and Terndrup TE: The impact of moderate ambient temperature variance on the relationship between oral, rectal, and tympanic membrane temperatures Clin Pediatr 1991, 30(4 suppl):6 I-64

53. Erickson RS and Kirklin SK: Comparison of ear-based, bladder, oral, and axillary methods for core temperature measurement Crit Care Med 1993, 2 I (10): 1528-1534.

54. Smitz S, Giagoultsis T, Dewe' W and Albert A: Comparison of rectal and infrared ear temperatures in older hospital inpatients J Am Geriatrics Society 2000, 48(I):63-66.

55. Nichols GA and Glor BAK: A replication of rectal thermometer placement studies Nurs Res 1968, I7(4):360-361.

56. Craig JV, Lancaster GA, Williamson PR and Smyth RL: Temperature measured at the axilla compared with rectum in children and young people: Systematic review BMJ 2000, 320(7243): $1174-1178$.

57. Cusson R, Madonia JA and Taekman JB: The effect of environment on body site temperatures in full-term neonates Nurs Res 1997, 46(4):202-207.

58. Fulbrook P: Core temperature measurement: $\mathbf{A}$ comparison of rectal, axillary, and pulmonary artery blood temperature Intensive \& Crit Care Nurs 1993, 9(4):2 17-225.

59. Fulbrook P: Core temperature measurement in adults: $A$ literature review J Adv Nurs 1993, 18(9): | 45 I-1460.

60. Bland JM and Altman DG: Statistical methods for assessing agreement between two methods of clinical measurement Lancet 1986, I(8476):307-310. 
61. Gardner $M$ J and Altman DG: Confidence intervals rather than $\mathbf{P}$ values: estimation rather than hypothesis testing $B M J$ 1986, 292:746-750.

62. McKenzie NE: The thermometry page:issues Sponsored by Kendall. 2001 , October 4 [http://www.graduateresearch.com/thermometryl issues.htm]. May 3, 200

63. Altman DG and Bland JM: Measurement in medicine: the analysis of method comparison studies The Statistician 1983, 32:307317.

64. Erickson RS and Woo TM: Accuracy of infrared ear thermometry and traditional temperature methods in young children Heart Lung 1994, 23(3): 181-195.

65. Fallis $W M$ and Christiani P: Neonatal axillary temperature measurements: A comparison of electronic thermometer predictive and monitor modes JOGNN 1999, 28(4):389-394.

66. Stephen SB and Sexton PR: Neonatal axillary temperatures: Increases in readings over time Neonat Netw 1987, 5(6):25-28.

67. Nichols GA, Fielding JJ, McKevitt RK and Posner I: Taking oral temperatures of febrile patients Nurs Res 1969, 18(5):448-450.

68. Robinson JL, Seal RF, Spady DW and Joffres MR: Comparison of esophageal, rectal, axillary, bladder, tympanic, and pulmonary artery temperatures in children J Pediatr 1998, 133(4):553556 .

69. Nagy E: Gender-related differences in rectal temperature in human neonates Early Hum Dev 200I, 64(I):37-43.

\section{Pre-publication history}

The pre-publication history for this paper can be accessed here:

http://www.biomedcentral.com/1472-6955/2/1/prepub

Publish with Bio Med Central and every scientist can read your work free of charge

"BioMed Central will be the most significant development for disseminating the results of biomedical research in our lifetime. "

Sir Paul Nurse, Cancer Research UK

Your research papers will be:

- available free of charge to the entire biomedical community

- peer reviewed and published immediately upon acceptance

- cited in PubMed and archived on PubMed Central

- yours - you keep the copyright 